\title{
O SENTIDO DE “ESTRANHO” EM LESLIE SILKO E KAKA WERÁ JECUPÉ identidades culturais, deslocamento e terra
}

Lúcia Helena de Azevedo Vilela

UFMG

\begin{abstract}
RESUMO
Análise da narrativa da trajetória pessoal de personagens que revelam sua perplexidade enquanto sujeitos indígenas diante de experiências de deslocamentos forçados e perda da ligação com a terra e com o lar. O estudo é realizado à luz do conceito de "estranho" ou estranhamento de Homi Bhabha e focaliza a personagem revolucionária, Angelita La Ecapía, em Almanac of the Dead, e o narrador de Todas as vezes que dissemos adeus. O texto procura enfatizar elementos que fazem emergir a força política da narrativa ao revelarem que luta pelo espaço entre fronteiras e diversas esferas de ação ocasiona sentimentos contraditórios e muitas vezes traumáticos para os sujeitos em questão.
\end{abstract}

\section{PALAVRAS - CHAVE}

indígenas norte-americanos, indígenas brasileiros, literatura, o estranho.

O sentido de identidade proporcionado pelo pertencimento a um grupo é intensamente afetado por diversos tipos de opressão social ou cultural. O deslocamento compulsório de um local conhecido para um desconhecido caracteriza um desenraizamento forçado dos povos e uma força desagregadora de sua memória. As identidades culturais dos povos indígenas estão intimamente vinculadas à terra - força agregadora de traços culturais e históricos e aliada aparentemente silenciosa de seus antepassados. Para a autora indígena norte-americana Leslie Marmon Silko, a força da terra é tão grande que, em sua visão, "os seres humanos podem profanar apenas a si mesmos; a Mãe Terra é inviolável". ${ }^{1}$ Historicamente, a violência inerente aos processos de colonização e aculturação traz consigo um processo de deslocamento resultante da ocupação do espaço motivada por práticas hegemônicas. O deslocamento forçado dos povos indígenas produz rompimentos e um sentido de desorientação. Se por um lado, como diz Silko, a terra é inviolável, o distanciamento do sentido primordial de ligação com ela, motivado por constantes deslocamentos

${ }^{1}$ Moore. Silko's Blood Sacrifice, p. 157. As citações de textos em inglês foram traduzidas pela autora. 
compulsórios, pode gerar um sentimento de desistência, como observa o autor indígena brasileiro Kaka Werá Jecupé em sua narrativa autobiográfica:

Pelas aldeias do litoral, ouvia histórias de séculos, ouvia tristes cantigas guaranis, rememorando descaminhos. Um labirinto de saudades que os caciques contavam. Da terra sem males. Presa em migalhas na boca dos guaranis, guardada na memória dos anciões. (...) Aprendi o trajeto da busca. Cada trilha. Cada pausa. Cada sim e cada não. Cada razão e cada desmoronamento. Morei entre seres cansados de busca. Foi triste. Um guerreiro não é derrotado quando morre em luta. Ele é derrotado quando desiste. (...) Isso eu aprendi quando vi a desistência estampada nos olhos dos guaranis daquela região. Viviam desistidos de si. Sem música interior. Obstruídos pelas ruínas da terra sem males da memória. ${ }^{2}$

O sentido de perda que Jecupé tão bem define como "desistência estampada nos olhos" ou obstrução "pelas ruínas da terra sem males da memória” é motivado justamente pelo desligamento causado pelos constantes deslocamentos a que esses povos foram submetidos. A força implícita no sentido de inviolabilidade da terra mencionada por Silko dificilmente pode ser herdada por aqueles que se sentem seus órfãos. Neste texto, eu argumento que o sentido de desagregação e desorientação observado nas obras aqui examinadas de Kaka Werá Jecupé e Leslie Marmon Silko é resultante dos constantes deslocamentos a que os povos indígenas têm sido submetidos ao longo da história. Argumento, portanto, que o sentido de identidade das personagens dessas obras parece estar afetado por um estranhamento de si mesmas, motivado por contínuos processos de deslocamento, que são, na verdade, formas de opressão cultural. $O$ termo deslocamento é utilizado para descrever a experiência daqueles que, como resultado do colonialismo, "têm sido assentados em um local que, devido a práticas coloniais hegemônicas, precisa, em um certo sentido, ser "reinventado" através da linguagem, da narrativa e do mito."

Refiro-me, aqui, portanto, de forma mais ampla, a todos os seres que estão literal e metaforicamente deslocados, colocados em um sistema que deixa a cultura de lado e ignora seus valores em favor de suas próprias práticas hegemônicas. Homi Bhabha utiliza o termo freudiano referente ao sentido de "estranho", ou estranhamento, para definir o sentimento provocado pela perda do espaço conhecido e pela consciência da existência de um espaço intersticial de reflexão. $\mathrm{Na}$ análise das obras dos dois autores indígenas aqui focalizados, cujas narrativas situam-se no espaço entre culturas, considero extremamente relevante e politicamente crucial se levar em conta os processos de articulação de diferenças culturais, pois, como argumenta Bhabha, "o que é teoricamente inovador e politicamente crucial é a necessidade de passar além das narrativas de subjetividades originárias e iniciais e focalizar aqueles momentos ou processos que são produzidos na articulação das diferenças culturais". ${ }^{4}$

Para Bhabha, o mencionado sentido de "estranho" refere-se a um sentimento motivado pela falta do espaço da casa, ou do lar, em inglês, unhomely, que de uma certa forma traduz o desconforto definido por Freud como unheimlich, ao mesmo tempo familiar e estranho. Esse sentido de "estranho" pode estar também no espaço liminar entre as noções

\footnotetext{
2 Jecupé. A terra dos mil povos, p. 27

${ }^{3}$ Ashcroft, Griffiths e Tiffin. Key Concepts in Post-Colonial Studies, p. 73.

${ }^{4}$ BhabHa. O local da cultura, p. 20.
} 
de público e privado. Bhabha explica esse sentimento : "Estar estranho ao lar [unhomed] não é estar sem-casa [homeless]; de modo análogo, não se pode classificar o "estranho" [unhomely] de forma simplista dentro da divisão familiar da vida social em esferas privada e pública." ${ }^{5}$

Da forma como o vejo aqui, o sentido de "estranho" refere-se a um momento crucial para o autor indígena, posterior ao deslocamento já mencionado, em que se percebe que os limites entre o lar e o mundo tornam-se confusos, fazendo com que o público e o privado se mesclem, forçando uma visão dividida e desorientadora. Apesar de esse conceito estar relacionado aos estudos da condição colonial e pós-colonial, Bhabha afirma que ele tem ressonância nas mais diversas situações em que é negociado o poder da diferença cultural em vários locais trans-históricos. Como afirma Bhabha, "nesse deslocamento, as fronteiras entre a casa e o mundo se confundem e, estranhamente, o privado e o público tornam-se parte um do outro, forçando sobre nós uma visão que é tão dividida quanto desnorteadora". ${ }^{6}$ Observa-se que os sujeitos das sociedades indígenas, e em especial as personagens criadas por Jecupé e Silko, muitas vezes não falam de si enquanto indivíduos, mas sim enquanto membros de uma comunidade indígena. Suas narrativas situam-se, em grande parte, no espaço liminar entre a identidade pessoal e a coletiva. Assim sendo, as noções de público e privado, da forma como trata Bhabha, não podem ser entendidas da maneira como o são no pensamento ocidental. No caso das personagens indígenas, o sentido de estranhamento não se vincula à mescla entre o público e o privado, mas à mescla da fronteira entre o espaço cultural indígena e o espaço cultural da sociedade dominante, que, de alguma forma, podem ser equacionados com as noções de privado e público. Da forma como enfatizo aqui, essa mescla é motivada por constantes deslocamentos compulsórios, trazendo, conseqüentemente, novos signos de identidade.

Em Almanac of the Dead, Silko retrata a formação de novos signos de identidade ao combinar algumas características das sociedades indígenas tradicionais com alguns elementos das teorias sociais ocidentais, ao tratar de questões relacionadas à devolução das terras indígenas. Silko revela a perplexidade da personagem central de uma das seções da obra, Angelita La Escapía, diante das faces desfiguradas de seu povo. O embate de Angelita é com os valores da sociedade branca capitalista e com a internalização de alguns desses valores pelos próprios membros de sua comunidade, o que dificulta a recuperação das terras indígenas, violentamente arrebatadas dos primeiros habitantes das Américas durante o processo de colonização. Em sua luta, Angelita se vale, principalmente, dos argumentos de Karl Marx. Na abordagem de Silko, passado e presente se mesclam em quinhentos anos de história. Para situar melhor sua obra, é importante lembrar que, publicado em 1991, Almanac of the Dead chega ao público após quatorze anos da publicação de sua obra mais conhecida, Ceremony (1977). Para alguns críticos norte-americanos, como Sven Birkerts, por exemplo, Almanac of the Dead situa-se na esfera da 'ficção radical', ${ }^{7}$ ou seja, lembra a ficção politicamente engajada do início do século vinte. O crítico acusa

\footnotetext{
${ }^{5}$ BHABHA. O local da cultura, p. 29-30.

${ }^{6}$ Bнавна. O local da cultura, p. 30.

${ }^{7}$ O crítico é citado por Caren Irr (1999). O ensaio mencionado é: Sven Birkerts, Apocalipse Now, New Republic (4 nov. 1991), 41.
} 
Silko de ingenuidade e delírio, de fugir da realidade, ao retratar os oprimidos do mundo como capazes de se libertarem de seus entraves e retomarem o que, de fato, lhes pertence. Essa crítica se baseia na visão de Birkerts sobre as estruturas de poder e a psicologia do oprimido, considerando, portanto, a impossibilidade de povos oprimidos organizarem uma rebelião e libertarem a si próprios, como narra Silko em sua obra. O crítico não compreende que o conceito de tempo de Silko não se prende às convenções da história oficial. Para a autora, de acordo com sua protagonista, Angelita, o tempo não se limita às noções de passado, presente e futuro. Ela afirma, por exemplo, que conhece Marx há séculos. Angelita se apaixona, essencialmente, pelo conceito de Marx de tempo e história, como lembra Caren Irr. ${ }^{8}$ Contrapondo-se ao ensaio de Birkerts, o estudo crítico de Irr esclarece que Silko trabalha com o conceito indígena de tempo e apropria-se da terminologia utilizada pelo crítico para denominar a obra como uma reescrita pós-moderna da ficção radical. Um exemplo do conceito de Silko do tempo é que, para Angelita, Marx habita o presente. Para ela, Marx é parte do presente uma vez que enfatiza os paradoxos da memória, enquanto que seus seguidores situam-se no passado porque preferem esquecer esse passado.

Angelita encontra uma correspondência entre a visão de Marx da história e o sentido de história para os povos indígenas, ou seja, a história está inserida em um presente constante, ou um passado presente. Angelita admira Marx por ter se inspirado na organização comunitária dos povos indígenas e em seu cultivo constante da memória, através das narrativas orais. Quando Marx ouviu as histórias dos trabalhadores, das crianças oprimidas e das mães que precisavam drogar seus filhos com ópio para que pudessem trabalhar dezesseis horas por dia, ele estava buscando a história oculta dos povos silenciados para ativar o passado e torná-lo sempre presente. É este conceito de história presente de Marx que fascina Angelita. Trata-se da noção indígena de passados presentes.

Em Almanac of the Dead podem-se encontrar elementos das culturas de origem da autora em uma rede de multiplicidade: o universo ficcional da obra revela uma fragmentação das personagens, tendo como pano de fundo uma atmosfera de decadência, aliada a uma espécie de idolatria à tecnologia, trazendo à tona temas médicos como o da comercialização de plasma e de órgãos humanos. Nesse contexto, Silko mostra, ainda, o plano de um exército de sem-casa que pretende derrubar o governo. No amálgama de todo esse mundo fragmentado, na região desértica de Tucson, Arizona, a autora utiliza a fórmula mítica dos almanaques Maia que traz o conhecimento da história, da tecnologia e da religião inserido na narrativa.

Com a abordagem do tema do levante de um exército de sem-casa, Silko faz com que sua obra se torne verdadeiramente imbuída do caráter profético do almanaque Maia. Os acontecimentos ocorridos em Chiapas, após a publicação do romance, fazem emergir uma espécie de reforço desse caráter profético da narrativa, como aponta Daria Donnelly:

Em um ensaio recente, a própria Silko se mostra satisfeita e acha interessante o fato de que Almanac of the Dead parece ter prognosticado os então imprevisíveis levantes dos Zapatistas Maia em Chiapas em 1994. O romance acontece parcialmente em Chiapas e uma inquietação revolucionária ali existente marca o início de uma insurreição indígena e a retomada das Américas.(...) A tendência profética de Almanac:

${ }^{8}$ IRr. The Timeliness of Almanac of the Dead, p. 234. 
e seu tratamento de eventos contemporâneos reduz as barreiras entre o mundo do livro e o mundo no qual o leitor vive de uma forma tão bem elaborada que o romance se torna um meio confiável através do qual se podem interpretar os acontecimentos globais em curso. ${ }^{9}$

Apesar de não ser a análise específica da questão dos movimentos sociais um dos objetivos deste trabalho, a menção a eles, através da citação de Donnelly, se justifica aqui por tratar-se de um exemplo importante dos resultados de uma reflexão em que o profético e o histórico estão presentes. Esse aspecto revela mais um espaço liminar, que se inclui no sentido de "estranho", ou seja, um espaço entre as noções de eventos proféticos ou míticos e eventos históricos. É como se um roteiro ficcional elaborado por Silko a partir de um almanaque mítico passasse a ser executado dentro de uma realidade histórica. Os acontecimentos históricos em Chiapas colocam por terra, também, a sustentação teórica de Sven Birkets, crítico do caráter revolucionário da temática de Silko, já mencionado anteriormente, que considera a marcha dos sem-casa absurda do ponto de vista histórico, já que, segundo ele, os oprimidos não estão habilitados para se libertarem de suas amarras e retomarem o que lhes pertence. Contrariando as premissas de Birkets, a obra de Silko provoca uma fissura em um pensamento hegemônico através da erosão paulatina de suas bases.

Assim sendo, em meio a uma variedade imensa de fatos e argumentos, Almanac of the Dead apresenta, de diversas formas, teorias políticas disseminadas na narrativa. A combinação inusitada, realizada por Silko, de diferentes tempos e espaços geográficos passa dos Estados Unidos ao México, da África às Américas e chega ao chamado Quinto Mundo. A combinação de tempos e espaços geográficos e a variedade de personagens descritas por Silko refletem o caráter provisório do sujeito pós-moderno, confrontado, no dizer de Stuart Hall, por "uma multiplicidade desconcertante e cambiante de identidades possíveis". ${ }^{10}$ Ao colocar sua narrativa no trânsito entre fronteiras e retratar uma líder indígena engajada na luta pela devolução das terras de seu povo, Silko reforça sua identificação com as idéias de Marx, sem contudo limitá-las ao espaço geográfico e histórico do homem Marx ou do marxismo. A identidade de Angelita tem as características cambiantes do sujeito pósmoderno definido por Hall. Tem, evidentemente, a mescla cultural entre a sociedade indígena à qual pertence e a cultura branca dominante. Encontra-se, portanto, naquela situação de sentir-se unhomely, Silko procura retratar a inquietação que aqui chamo de "estranho" através de um discurso da memória que resulta em uma fusão tempo-espaço.

A memória cultural dos povos das Américas está viva nas palavras de Angelita: "A cada dia, desde a chegada dos europeus, em algum lugar na vastidão das Américas o sol se levanta sobre a resistência e a revolução dos povos indígenas americanos. Ouçam a história que os europeus, até mesmo os marxistas, esperam que nós indígenas americanos esqueçamos". ${ }^{11}$

Angelita vê o mundo da política de forma ampla e com seus próprios olhos. Não se deixa levar pelas interpretações alheias. Sua percepção de Marx, por exemplo, é

\footnotetext{
${ }^{9}$ Donnelly. Old and New Notebooks, p. 247-8.

${ }^{10}$ Hall. A identidade cultural na pós-modernidade, p. 14.

${ }^{11}$ SiLKo. Almanac of the Dead, p. 527.
} 
extremamente íntima e pessoal. Trata-se da visão de quem mastigou e digeriu os elementos, apropriou-se deles e reproduziu-os de maneira própria. Em uma assembléia indígena com a finalidade de se discutirem formas radicais de devolução das terras indígenas, Angelita dá a sua visão híbrida de Marx, na qual está incluída a leitura do indígena espoliado pelo homem branco:

"Agora quero lhes dizer uma coisa sobre mim mesma porque muitos rumores andam circulando. Rumores sobre mim e o marxismo. Rumores sobre mim e o fantasma de Karl Marx!" (...) "Isso é pessoal, mas as pessoas desejam saber o que eu penso; querem saber se sou marxista". Angelita sacode a cabeça negativamente. "Os marxistas não querem dar a terra indígena de volta. Nós dizemos para o inferno com todos os marxistas que se opõem à devolução da terra indígena!” (...) Que os marxistas vão para o inferno! Que os capitalistas vão para o inferno! Que o homem branco vá para o inferno! Nós queremos a mãe terra". (...) "O marxismo é uma coisa! Marx o homem é outra," Angelita havia dito ao dar início a sua defesa de Marx. Os assim chamados discípulos de Marx freqüentemente desgraçaram o seu nome, do mesmo modo como Jesus foi desgraçado pelos crimes de seus ditos seguidores, os papas da Igreja Católica. ${ }^{12}$

A Angelita concebida por Silko revela sua ligação com o local quando defende como causa principal a devolução das terras indígenas. Liga-se, ainda, ao global quando transpõe fronteiras culturais, através da educação e do mundo acadêmico, quando retira da ideologia branca aquilo que lhe interessa. Situa-se, ainda, naquele espaço intersticial que possibilita a negociação, entre a casa e o mundo, o espaço do "estranho", que é uma visão "dividida" e "desnorteadora", como diz Bhabha ${ }^{13}$, mas também impulsionador de ações transformadoras.

Marx, o homem europeu, é esmiuçado e explicado, em termos simples, por Angelita para homens e mulheres indígenas de diferentes gerações em seus argumentos para a defesa da devolução das terras, com a finalidade de congregá-los para a luta. Relembrando a força ancestral que lhe é culturalmente conferida, a protagonista Silko é agregadora do grupo étnico no qual se inclui historicamente e por escolha política. O sentido de "estranho", ou estranhamento, diante dos rostos que procuram acreditar que ela será capaz de lhes devolver a força que a terra lhes confere é que impulsiona Angelita a buscar argumentos que tornem viável a união desse povo em torno da luta pela devolução da terra. Sempre empurrados para mais adiante nas terras de seus ancestrais, os povos indígenas norte-americanos têm na ficção de Silko uma forma de manifestarem sua indignação - através de uma revolução silenciosa de um exército de sem-casa. O deslocamento voluntário desse grupo rumo ao norte revela uma tomada de decisão: ao invés de serem movidos, passam a um movimento autônomo em busca do que lhes pertence.

Os deslocamentos espaciais forçados estão também presentes na narrativa de Kaka Werá Jecupé, que, através de seu narrador, revela seu estranhamento diante da vida às margens de uma represa poluída e de uma metrópole - São Paulo. O próprio título da obra, Todas as vezes que dissemos adeus, sugere os constantes movimentos de partida e chegada de diferentes lugares. Através de sua narrativa autobiográfica, o jovem narrador de Jecupé conta como teve de se deslocar do norte para o sul do Brasil com sua família que pertencia

\footnotetext{
${ }^{12}$ Silko. Almanac of the Dead, p. 519.

${ }^{13}$ BнавнA. O local da cultura, p. 30.
} 
à nação dos Txukarramães: "Eu era muito pequeno na década de 60 quando meus pais foram morar próximo à aldeia de Krukutu, da nação guarani, que margeia a represa Billings na zona sul da cidade de São Paulo, horizonte de meu nascimento, oposto ao Norte de onde viera o meu povo". ${ }^{14}$ As condições adversas e insalubres do local ao qual tem de se adaptar acabam por fazer com que o narrador adoeça. $O$ corpo reage com feridas às condições ocasionadas pelo deslocamento da família, que conserva o tratamento tradicional dos povos indígenas, através das ervas que a terra lhe oferece:

Fui aprender a nadar, tempos depois, com meu amigo, e mergulhamos nas grossas águas da represa que cercava e delimitava a aldeia. Ficamos doentes. Meu corpo inteiro encheu-se de feridas. Foi preciso passar deitado todas as fases da lua e um tratamento com as sagradas ervas que a mãe cultivava para que eu pudesse me mexer. ${ }^{15}$

O jovem protagonista da narrativa de Jecupé tem de enfrentar o escárnio das pessoas que vêem a ele e sua família como diferentes e sem asseio quando ele e seus amigos tentam trocar peças de artesanato por comida. Os brancos pagam a eles o que o narrador qualifica de esmola. Jecupé ouve-os dizer: "Sujos, nem banho tomam". ${ }^{16}$

A família de Jecupé havia passado por um deslocamento forçado do norte para o sul do Brasil. Em São Paulo, é novamente expulsa das proximidades da aldeia onde se instala e é informada de que deveria sair das terras onde morava porque estas não lhe pertenciam e sim a imigrantes brancos. A família teve de se mudar para o litoral, já que descendentes de imigrantes alemães diziam possuir documentos que permitiam que a "civilização" expropriasse e destituísse os primeiros brasileiros de sua ligação com a terra. Jecupé comenta com amargura sobre o poder das leis:

$\mathrm{Na}$ aldeia havia algo de podre exalando da represa.

Um dia chegou um senhor com uns papéis na mão dizendo que o lugar onde morávamos era dele, doado por D. Pedro II.

- Filho, procure esse tal D. Pedro que quero falar com ele. - disse o pai.

Estou procurando até hoje.

"Como? Não havia nada quando aqui chegamos, além dos nossos parentes guaranis do outro lado da represa", pensava meu pai.

Fomos expulsos.

Anos depois descobri que aquela região onde morávamos fora doada, no século XVIII, pelo então imperador do Brasil para imigrantes alemães. Sendo que uma pequena parte tinha prosperado e virado a cidade de Santo Amaro, e aqueles lugares mais afastados tinham sido largados aos descendentes possíveis desses imigrantes.

Nessa parte do país a civilização é mais moderna. Lá no Norte ainda expulsa-se à bala. Aqui documentos do imperador.

A sagrada trilha nos levou ao litoral". ${ }^{17}$

O sentido de "estranho" de que nos fala Bhabha está presente nas palavras do narrador ao relatar sua dificuldade em se adaptar ao ambiente hostil da cidade e à falta do verde da mãe-terra: "Levei um bom tempo até retomar a vida pelas trilhas tranqüilas da infância.

\footnotetext{
${ }^{14}$ Jecupé. A terra dos mil povos, p. 20.

${ }^{15}$ JeCupé. A terra dos mil povos, p. 20.

${ }^{16}$ Jecupé. A terra dos mil povos, p. 29.

${ }^{17}$ JeCupé. A terra dos mil povos, p. 26.
} 
Uma paisagem muda naturalmente, mas naquele lugar era como se ela se desmanchasse aos pedaços, quando menos se esperava. Como a pintura no rosto quando se espalha e borra. Nessa borragem, que era a cidade pulsando nos vilarejos, o verde rareava dos nossos olhos". ${ }^{18}$

A avó do narrador representa para ele uma ligação digna com a tradição bem enraizada de seu povo. Ela é uma protetora ferrenha da dignidade de seu povo. Quando visita a família de Jecupé pela primeira vez, ela observa: "E vim aqui só para te dizer isso. Nós não podemos apagar o sol que o criador pôs dentro de nós". ${ }^{19}$ As palavras dela soam de forma tão poderosa para ele que o narrador pensa que ela sempre estivera ali com eles, apesar de não tê-la visto desde que eles deixaram o norte para ir para São Paulo. A avó do narrador representa uma ligação ancestral com a terra e seus valores que são essenciais para a dignidade de seu povo.

O elemento central da narrativa de Jecupé é que ele diferencia as características de sua cultura nativa - que estivera adormecida dentro dele até então - daquela do assim chamado mundo civilizado. Portanto, no cerne de sua narrativa, o seu retorno ao universo tradicional de sua cultura nativa estabelece a sua autoconsciência, sua própria identidade e a de seu povo. Quando compreende que a fonte de todos os seus problemas era a perda de sua ligação com a terra e o mundo de seus ancestrais, Jecupé claramente decide escolher seguir o seu caminho anteriormente perdido.

O narrador encontra estratégias específicas não só para lidar com as agruras de viver entre mundos diferentes como também para se comunicar com seus leitores e se definir como porta-voz de um povo que tem tido tão pouco espaço para se fazer ouvido. Jecupé parece escrever para ajudar seus leitores a identificar as características da cultura dos Txukarramães ou dos Guaranis dos estereótipos de índios como são vistos e reconhecidos pela sociedade branca majoritária das cidades grandes nas quais ele era visto como um pária.

Como vimos, as fronteiras entre esferas diversas ocasionam sentimentos contraditórios e muitas vezes traumáticos. Tanto Silko quanto Jecupé revelam o caráter inovador de suas obras ao mostrarem a perplexidade de sujeitos indígenas diante das experiências dos deslocamentos forçados e da perda da ligação com a terra e com o lar. Nesse sentido, suas narrativas têm um papel político crucial. Como lembra Bhabha, "o momento do estranho relaciona as ambivalências traumáticas de uma história pessoal, psíquica às disjunções mais amplas da existência política”. ${ }^{20}$ Silko e Jecupé demonstram o peso da questão política da luta pelo espaço indígena, através da personagem revolucionária, Angelita La Escapía, em Almanac of the Dead, e através do narrador de Todas as vezes que dissemos adeus.

\footnotetext{
${ }^{18}$ Jecupé. A terra dos mil povos, p. 21.

${ }^{19}$ JeCupé. A terra dos mil povos, p. 28.

${ }^{20}$ BнавнA. O local da cultura, p. 32.
} 


\section{A B STRACT}

This essay is an analysis of the narrative of the personal trajectory of characters who reveal their perplexity as Native individuals in their experience of compulsory displacement and loss of attachment to the land and to their home. The study is made in the light of Homi Bhabha's concept of "unhomely" and it focuses on the revolutionary character Angelita La Ecapía, in Almanac of the Dead, and on the narrator of Todas as vezes que dissemos adeus (Whenever We Said Goodbye). The text tries to highlight elements that make the political force of the narrative emerge as they reveal that the fight for the space between borderlands and different spheres of action may cause contradictory feelings which are most traumatic for the subjects in question.

\section{KEY WORDS}

native Americans, native Brazilians, literature, the unhomely.

\section{REFERÊNCIAS BIBLIOGRÁFICAS}

Ashcroft, Bill; Griffiths, Gareth; Tiffin, Helen. Key Concepts in Post-Colonial Studies. Londres/Nova York. 1998.

Barnett, Louise; Thorson, James L (Ed.). Leslie Marmon Silko: A Collection of Critical Essays. Albuquerque: Univ. of New Mexico Press, 1999.

BhabHa, Homi. O local da cultura. Myriam Ávila, Eliana Reis e Gláucia Gonçalves (Trad.) Belo Horizonte: Editora UFMG. 2001.

Donnelly, Daria. Old and New Notebooks: Almanac of the Dead as Revolutionary Entertainment. In: BARnetT, Louise; Thorson, James (Ed.). Leslie Marmon Silko: A Collection of Critical Essays. Albuquerque: Univ. of New Mexico Press, 1999, p. 245-259.

Hall, Stuart. A identidade cultural na pós-modernidade. Tomaz Tadeu da Silva e Guacira Lopes Louro (Trad.). Rio de Janeiro: DP\&A, 1997.

Hernandez, Jennifer Browdy de. The Plural Self: The Politicization of Memory and Form in Three American Ethnic Autobiographies. In: Singh, Amritjit; Skerrett JR, Joseph T.; Hogan , Robert E. (Ed.). Memory and Cultural Politics: New Approaches to American Ethnic Literatures. Boston: Northeastern Univ. Press, 1996, p. 41-59.

IRr, Caren. The Timeliness of Almanac of the Dead, or a Postmodern Rewriting of Radical Fiction. In: Barnett, Louise; Thorson, James (Ed.). Leslie Marmon Silko: A Collection of Critical Essays. Albuquerque: Univ. of New Mexico Press, 1999, p. 223-244.

Jakoski, Helen. Leslie Marmon Silko: A Study of the Short Fiction. Nova York: Twayne Publishers, 1988.

Jecupé, Kaka Werá. A terra dos mil povos: história indígena do Brasil contada por um índio. São Paulo: Fundação Peirópolis, 1998.

JeCupé, Kaka Werá. Todas as vezes que dissemos adeus. São Paulo: Fundação Phytoervas, [s.d.]. Loomba, Ania. Colonialism/Postcolonialism. London \& New York: Routledge, 1998. 
Moore, David L. Silko's Blood Sacrifice: The Circulating Witness in Almanac of the Dead. In: Barnett, Louise; Thorson, James (Ed.). Leslie Marmon Silko: A Collection of Crtical Essays. Albuquerque: Univ. of New Mexico Press, 1999, p. 149-183.

Silko, Leslie Marmon. Almanac of the Dead. Nova York: Penguin, 1992

Whitrow, G. J. O tempo na história: concepções do tempo da pré-história aos nossos dias. Maria Luiza X. de A. Borges (Trad.). Rio de Janeiro: Jorge Zahar, 1988. 